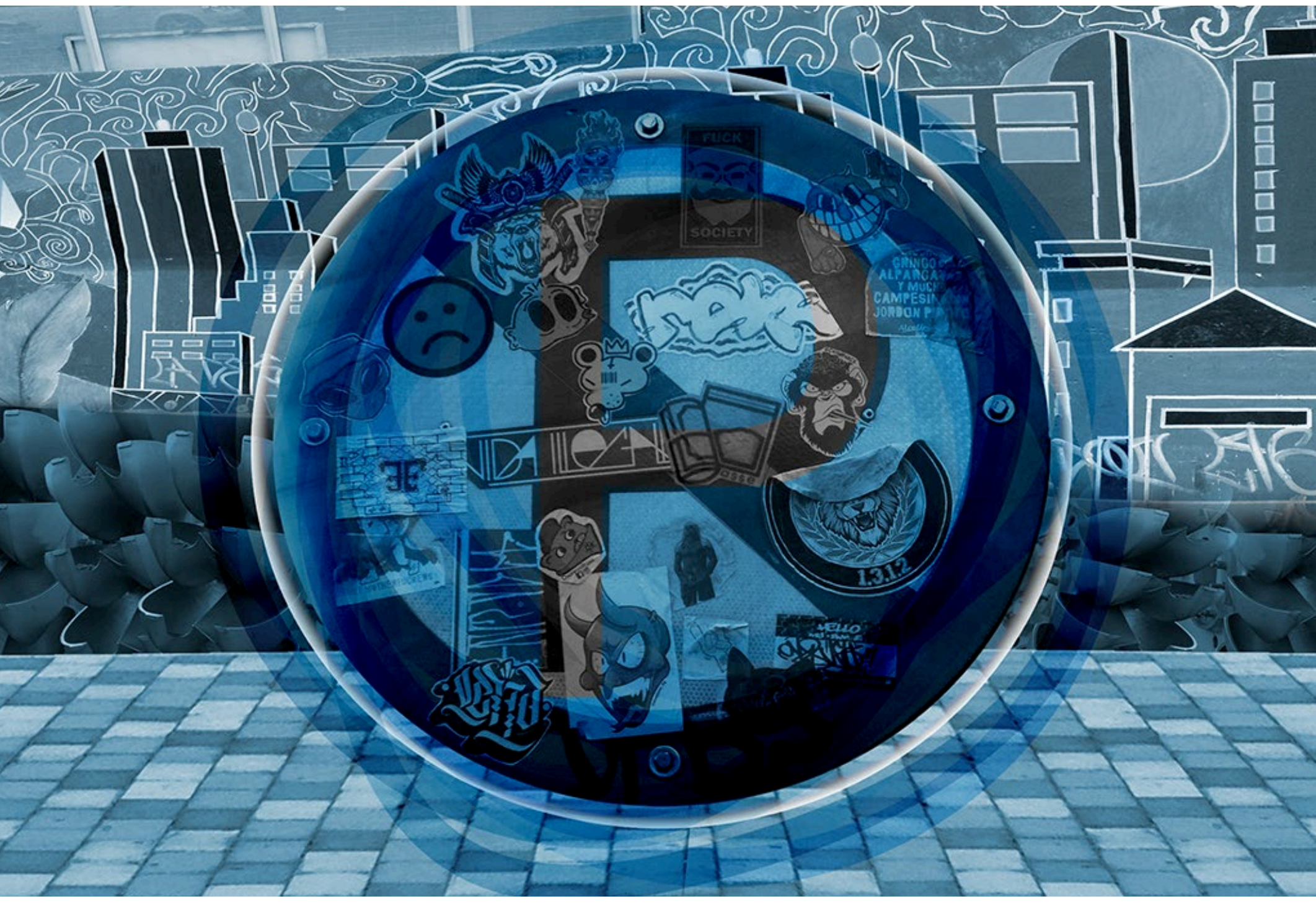

\title{
Medios interactivos: la brecha digital como agenciadora de la construcción de subjetividades
} Interactive media: the digital divide as an agency for the construction of subjectivities

Mídia interativa: o fosso digital como agência para a construção de subjetividades 


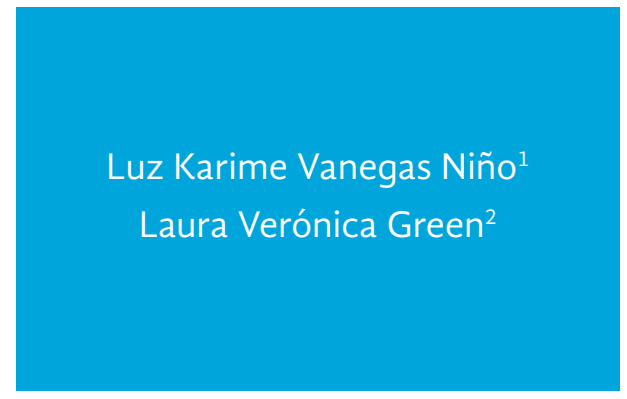

Magíster en Comunicación-Educación, Universidad Distrital Francisco José de Caldas; correo electrónico: luzkarimevn@gmail.com

Magíster en Comunicación-Educación, Universidad Distrital Francisco José de Caldas; correo electrónico: Iveronicajg.Iv@gmail.com

Fecha de recepción: 8 de junio de 2018 / Fecha de aprobación: 26 de septiembre de 2018

\section{Resumen}

El presente artículo reporta los resultados de un estudio cualitativo y descriptivo llevado a cabo en una comunidad virtual de Bogotá, Colombia. El objetivo del estudio fue reflexionar acerca de la influencia de las nuevas Tecnologías de la Información y la Comunicación (TIC) en la representación de la subjetividad de los jóvenes. Los datos fueron recolectados a través de encuestas en línea y artefactos de interacciones en la comunidad virtual. El análisis mostró que la subjetividad de los jóvenes fue construida por la socialización dentro de la comunidad virtual y que usan las TICs para expresar sus emociones, pasiones, deseos y disgustos mientras interactúan con otros. Así, la Internet propicia un espacio para la producción de contenido heterogéneo, en donde los jóvenes comparten sus opiniones, rituales, discursos y saberes mientras asumen sentidos de pertenecía a la comunidad. Estas interacciones en línea modifican por completo el esquema tradicional de la comunicación unidireccional y permiten que cualquier receptor pueda convertirse en emisor.

Palabras clave: Subjetividad, TICs, construcción, interacción, comunidad virtual.

\section{Abstract}

This article reports the results of a qualitative and descriptive study undertaken in a virtual community of Bogota - Colombia. The objective of the study was to reflect on the influence of new Information Technologies and Communication (TIC) to represent young people subjectivity. Data were collected through surveys online and artifacts of interactions in the virtual community. The analysis showed that young subjectivity was built through socialization within the community virtual and that young people use ICTs to express their emotions, passions, desires and dislikes while interacting with others. Thus, the Internet propitiates a space for the production of heterogeneous content, where young people share their opinions, rituals, speeches and knowledge while assuming belonging meanings to the community. These online interactions completely modify the traditional scheme of unidirectional communication and allow any recipient to become an issuer.

Keywords: Subjectivity, ICTs, representation, interaction, virtual community.

\section{Resumo}

Este artigo relata os resultados de um estudo qualitativo e descritivo realizado em uma comunidade virtual de Bogotá Colômbia. O objetivo do estudo foi refletir sobre a influência de novas tecnologias de informação e Comunicação (TIC) em representação da subjetividade dos jovens. Os dados eles foram coletados por meio de pesquisas on-line e artefatos de interações no comunidade virtual A análise mostrou que o subjetividade dos jovens foi construída para socialização dentro da comunidade virtual e que usam as TIC para expressar suas emoções, paixões, desejos e desgostos enquanto interage com os outros. Assim, a Internet propicia um espaço para a produção de conteúdo heterogêneo, onde os jovens eles compartilham suas opiniões, rituais, discursos e conhecimento, assumindo significados de pertencia à comunidade. Essas interações on-line modificar completamente o esquema comunicação unidirecional tradicional e permitir que qualquer destinatário Tornese um emissor

Palavras-chave: Subjetividade, NTIC, construção, interação, comunidade virtual. 


\section{Introducción}

as cualidades tecnológicas de los nuevos medios de comunicación facilitan el encuentro entre los sujetos. En estas relaciones sociales surge la búsqueda de aspectos comunes y, como consecuencia, procesos que llevan a la construcción de subjetividad. El presente escrito tiene como objetivo principal reflexionar sobre la influencia de los medios digitales en la construcción de significados que dan sentido a diferentes modos de ser, vivir y pensar; de igual manera, busca comprender los fenómenos que se presentan en la brecha digital que afrontan los jóvenes para construir su subjetividad

Es imperativo, entonces, aclarar algunos conceptos centrales. Así, algunas características para conceptualizar a la "juventud", tomadas de Pérez (2002, citado en Machado, et al., 2008; pp. 2-3), son que ésta:

- Es un concepto relacional que adquiere sentido en la interacción con categorías como las de género, etnias y clase social.

- Es históricamente construida, puesto que los contextos social, económico y político configuran características concretas sobre el vivir y percibir lo joven.

- Es situacional, ya que responde a contextos concretos bien definidos.

- Está constituida por "hétero-representaciones" elaboradas por agentes o instituciones sociales externos a los jóvenes, y por autopercepciones de los mismos jóvenes.

- Se construye en relaciones de poder definidas por condiciones de dominación, centralidad o periferia, en las que se dan procesos complejos de complementariedad, rechazo, superposición o negación.

- Se produce, tanto en lo cotidiano, en ámbitos íntimos como los barrios, la escuela y el trabajo; como en lo "imaginado", en comunidades de referencia como la música, los estilos y la Internet.

De ahí que también podemos afirmar que la forma de vida de la mayoría de jóvenes está ligada a los diferentes espacios y recursos que las nuevas tecnologías permiten; conformando nuevas formas de socialización y expresión. Es por ello que cuando se habla de las interacciones adultos/medios de comunicación aparece el término "brecha digital", que alude a la:

Distancia existente entre áreas individuales, residenciales, de negocios y geográficas en los diferentes niveles socio-económicos en relación a sus oportunidades para acceder a las nuevas tecnologías de la información y la comunicación, así como al uso de Internet (OCDE, 2004, p. 5).
Es decir, la brecha digital define la distancia entre quienes pueden usar un aparato tecnológico (sobre todo, referido a ordenadores) y los que no, ya sea por motivos económicos, de formación, etc.

Nos encontramos, por ende, con una configuración cultural, social y personal de las tecnologías, pero también, recíprocamente, las personas, sus cuerpos y sus relaciones se ven transfiguradas por los usos y mediaciones tecnológicas. En este fenómeno, compartido entre personas y máquinas, no solo están implicados usuarios y artefactos, sino las condiciones de comercialización marcadas por operadores, servidores y propietarios de las plataformas, y las distintas regulaciones institucionales e informales de dichos usos y prácticas.

Verbigracia, la actualización de un perfil en una red social moviliza una pluralidad de actividades y formas de conocimiento social: como relaciones de género, encarnación y maneras de hacer y habitar el cuerpo ("embodiment") (Weis y Haber, 1999, pp. 143-62), pericias tecnológicas, reglas de etiqueta, habilidades lingüísticas, creatividad personal y colectiva o gestión emocional. Las tecnologías facilitan compartir las experiencias vividas al tiempo que contribuyen a crearlas y darles forma para quienes participan en procesos de subjetivación contemporáneos, de producción de sujetos en su doble acepción: configuración y transformación de subjetividades (Canclini, Cruces y Urteaga, 2012, pp. 6-10).

Igualmente, las tecnologías intervienen en la emergencia y mantenimiento de las formas de sujeción respecto de instituciones, grupos y otros individuos; el apego y dependencia hacia objetos $\mathrm{y}$ artefactos y la sujeción respecto a las ideas y concepciones que nos hacemos de nosotros mismos, que nos llevan a ser sujetos de autoconocimiento y de autoconciencia. La demanda de reconocimiento, presente en la mayoría de las relaciones interpersonales, es uno de los modos de sujeción y dependencia característicos de la formación del yo, sujeta a una mediación digital creciente. Ambos significados sugieren una manera de poder que nos subyuga y nos da forma como sujetos. Los dispositivos digitales participan de ambos aspectos: identidad, reflexividad y autoconocimiento, por un lado, y vigilancia, control, autocontrol y dependencia, por el otro (Foucault, 1982, p. 5).

\section{Conceptualización: subjetividad}

La subjetividad, según D’Angelo (1996, pp. 1-3), es una construcción de los seres humanos en el contexto social que parte 
de sus realidades de vida cotidiana en relación con otras personas, instituciones, estructuras sociales, la producción simbólica social, la naturaleza y el mundo de objetos materiales. Así, la subjetividad conforma una dimensión totalizadora de la experiencia y la praxis social, del mundo espiritual de las personas y sus condiciones sociales de vida.

Además, la subjetividad se entiende como un constructo que integra varias dimensiones del ser: el pensar, el querer (sentirdesear) y el hacer, en las que se implica, identifica y diferencia el individuo en tanto sujeto. En el constructo de la subjetividad se involucra el pensamiento y la acción con el fin de generar, elaborar e implementar experiencias de vida. De igual manera, ésta se transfigura en un proceso de significación social que tiene que ver con la generación común de símbolos enmarcada en la interacción; son las percepciones, representaciones colectivas, cohesión social, los afectos, conflictos interpersonales, estados anímicos de los individuos y de los grupos, las relaciones de poder y de sentir, entre otros aspectos, los que producen situaciones de intercambio que conforman las subjetividades.

Al reflexionar sobre la subjetividad, en la actualidad, es importante abarcarla en un contexto audiovisual y transmediático, que rige las prácticas comunicativas y atraviesa las representaciones de los partícipes de la comunicación digital interactiva. Es por ello que la subjetividad adquiere relevancia en el plano del yo y del nosotros, insertándose en ámbitos culturales de la época y en las formas simbólicas producidas por los sujetos mediante sus prácticas (Amador, 2014, p. 26). Cabe resaltar que estos dos factores permiten que los sujetos adquieran motivaciones, recursos $\mathrm{y}$ opciones para acontecer en el mundo. La cultura audiovisual y los repertorios transmediáticos, inscritos en las prácticas comunicativas, introducen otras racionalidades y nuevos capitales culturales.

Por tanto, al hablar de subjetividad se debería comprender el conjunto de manifestaciones expresadas en la cultura, el lenguaje (a través de las formas simbólicas) y los saberes (como capitales culturales nuevos), que en la actualidad repercuten en la construcción de subjetividad y permiten explicar cómo el sujeto ha llegado a ser lo que es y cómo puede llegar a ser algo en el futuro; un desenvolvimiento socio-cultural que privilegia lenguajes y saberes para ejercer acciones colectivas; cierta propensión a producir y publicar ideas y propuestas en torno a los sucesos del mundo de la vida; y el despliegue de ciertas habilidades que favorecen, no solo la interpretación de ideas y fenómenos, sino la producción de presencia (Amador, 2014, p. 49).
Otro eje esencial al abordar el concepto de subjetividad es su relación con las formas de comunicación y sus transformaciones en relación con los medios y las tecnologías. Así, la producción de la subjetividad en el contexto socio-cultural se determina por un conjunto de prácticas comunicativas que operan en el tiempo-espacio de la vida cotidiana. Esto permite afirmar que la subjetividad no es una dimensión del ser exclusivamente ligada a las contingencias de su conciencia o de su voluntad (Amador, 2014 , p. 85), puesto que los entornos que habitan los sujetos mueven fuerzas y poseen alcances que modifican sus formas de percibir, pensar y actuar.

Así, la subjetividad trata de aquellas formas de ser-estar en el mundo, en ella interviene la interiorización de las formas simbólicas y materiales que provienen de las orientaciones institucionales y de las estructuras sociales; las iniciativas individuales y colectivas que pueden llegar a producir sentido y afectar dichas estructuras y que parten de los mundos producidos en su vida cotidiana.

El programa cultural actual produce nuevas visualidades y sonoridades que fomentan prácticas comunicativas en un espaciotiempo que configura subjetividades hiper, trans mediales e interactivas que se expresan de diversas maneras. Según Amador (2014, p. 87), se pueden destacar seis grandes expresiones de estas subjetividades:

- Nuevas percepciones del tiempo y el espacio mediadas por el acceso a narrativas, géneros y formatos que amplían los sistemas de significación, lo que favorece otros modos de socialización, sensibilización y acceso a saberes.

- Construcción de identificaciones sociales auspiciadas por nuevos sistemas de intereses y necesidades que pueden potenciar lo común como opción de vida.

- Inmersión en transmediaciones que amplifican lo sensorial visual, lo auditivo y, eventualmente, lo táctil, como mediación que favorece la producción de repertorios senso-perceptuales, estéticos y cognitivos.

- Prácticas hipertextuales e hipermediales que posibilitan arquitecturas de participación.

- Saberes emergentes que se convierten en capitales culturales, caracterizados por la hipermedialidad, la interactividad y la

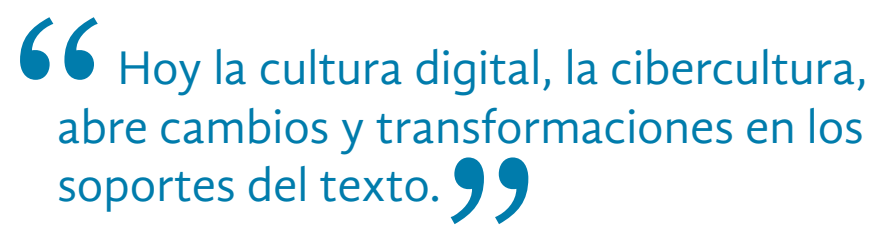


intertextualidad, los cuales favorecen la producción de sí, la colaboración y la participación.

- Deseos que se expanden y placeres que pueden ser vividos mediante el acceso a contenidos (de lo íntimo, lo prohibido, la tragedia y la derrota humana) sin filtros ni censuras.

Por ello, es importante resaltar que los jóvenes están pasando por un tránsito de la subjetividad moderna (mediada por la escuela y la familia), a subjetividades emergentes (visuales, transmediáticas, hipermediales e interactivas) que les permiten ser sujetos, comprender la realidad y habitar el mundo. Es la reafirmación del yo (múltiple) en espacios desterritorializados de la comunicación y la cultura, como posibilidad de coexistencia plural y singular; y la dimensión interactiva del yo-otro, la cual se apoya en las temporalidades y diacronías glocales que emergen de la nueva cultura audiovisual.

El carácter hipermedial de la subjetividad se reafirma en la construcción de mundos de vida cimentados en un "yo" con múltiples rostros y posibilidades de expresión. Se caracteriza por el esfuerzo que realizan estos sujetos por situar su mente y cuerpo en un espacio digital e interactivo (múltiple y evanescente), que implica narrar y narrar-se como otra opción de existencia (Amador, 2014, p. 90), en muchas ocasiones, su coexistencia y presencia en diversos sistemas de paso (redes sociales, blogs, videojuegos, canales de video, wikis, mensajes de texto, reproductores de video y música, etc.), posibilitan la re-creación permanente del yo.

Este elemento contemporáneo privilegia otras posibilidades de ser y habitar el mundo, mediante la conformación de redes y comunidades orientadas por nuevos sistemas de intereses y necesidades como opción de vida, a través de exploraciones que operan simultáneamente en el tiempo (multitasking, zapping, narrativas diacrónicas) y se relacionan con la vida cotidiana, la experiencia cultural y sus implicaciones en la relación yo-otro.

Así, según Amador (2014, p. 97), aunque el otro no es el reflejo del yo, sí supone la configuración de un tú con el que se construye la palabra y se crean medios para acontecer, los cuales implican la necesaria exploración del mundo cuya fuente de significado y afectación se encuentra en el ser del otro. Lo que subyace a todo encuentro entre el yo y el otro son puntos de vista que se incorporan al acontecimiento y la alteridad. De esta manera, se hace posible que el "yo" (múltiple) transite a un "yo" colectivo que se construye con los otros. El sujeto comunicativo e hipermedial halla explicación a su existencia a partir de los encuentros y desencuentros con otros, y no solo a partir de la exaltación de su yo.
El reconocimiento de comunidades virtuales que generan aprendizajes, y comparten intereses y necesidades con otros miembros, permite observar cómo a través de sus interacciones en línea se representa una dimensión de su propio "yo" y del "nosotros" dentro de dicho grupo. Ergo, la subjetividad es definida como una “dimensión del yo y el nosotros que está inextricablemente ligada al programa cultural de la época y a las formas simbólicas producidas por los sujetos mediante sus prácticas” (Amador, 2014, p.79).

La subjetividad es un proceso de construcción del propio sujeto en el que intervienen diversas circunstancias que se despliegan en el tiempo y el espacio. Es el reconocimiento de un "yo" como participante de una comunidad en el momento en que interactúa y participa voluntariamente y de diferentes formas. Dicha participación del individuo en un entorno virtual (Heeter, 1992, pp. 65-70) está dada por la capacidad de personalizarse a través de la foto de perfil o de un seudónimo seleccionado para ser reconocido como miembro activo de esta comunidad, generando mediaciones y reconocimiento por otros miembros.

Dicha forma de visibilización puede estar dada en diferentes formatos: videos, discusiones en línea, escritura, entre otros; al partir de estas estrategias se produce la identificación del "yo" entre los otros miembros de la comunidad. Sin interacción mediada por el lenguaje no es posible el reconocimiento de un sujeto, es allí donde se permite el desarrollo de acciones colectivas que llevan a producir y publicar ideas y propuestas en torno a los sucesos del mundo de la vida, a desplegar ciertas habilidades que favorecen la producción de presencia (Gumbrecht, 2005, pp. 185-191).

El "yo" se manifiesta desde diferentes perspectivas, así, los miembros de las comunidades virtuales proyectan su mente y su cuerpo con el propósito de "descifrarse, descifrar a otros y ser descifrados dentro de esta comunidad" (Amador, 2014, p. 86). Es decir, los participantes de las comunidades virtuales pueden reaccionar frente a diversos temas, generar discusiones, afirmar o cambiar de postulados, construyendo una presencia virtual que se desvela dentro de la comunidad y es reafirmada o negada por otros usuarios.

Entendamos la comunicación digital interactiva como la facilitadora para describir el mundo por medio de las experiencias vividas por cada uno de los participantes, y ver cómo las comparten y contribuyen a crear y dar forma a las experiencias grupales (Canclini, Cruces y Urteaga, 2012, p. 53). Es decir, este proceso presenta la racionalización de la vida que no se agota en la designación analógica de los objetos, sino en una esfera de la producción de sentido en la que interviene la representación de su "yo" como miembro de esta comunidad (Amador, 2014, p. 45).

El "yo" 
Nuevas formas de pensar el proceso de construcción de la subjetividad implican una reflexión cultural y tecnológica, pues estas esferas agencian las relaciones entre los sujetos, los espacios y los tiempos. La noción de des-temporalización, señalada por MartínBarbero (1991, p. 166), es uno de los rasgos más importantes y da cuenta de la diversidad temporal, geográfica, profesional y etérea de un ámbito virtual. Esto representa una nueva relación entre sujetosespacios-tiempos. Por su lado, Bourdieu (1985, pp. 723-744) reclama que la posibilidad de la interacción entre personas está estipulada por el espacio que ocupan en el campo social, que podría estar sujeto, entre otras, a su condición de clase y capital cultural.

\section{De la lectura desde el texto y el hipertexto; otros saberes}

En esta experiencia se analizaron las subjetividades, prácticas y representaciones asociadas al texto convencional y a los hipertextos, teniendo en cuenta que, desde la impronta de la cultura del impreso, el libro ha sido considerado el instrumento emblemático que sirvió para conservar la sabiduría colectiva y para la circulación del conocimiento. Hoy la cultura digital, la cibercultura, abre cambios y transformaciones en los soportes del texto, así como en el proceso de lectura concomitante. En tal sentido, Martín-Barbero expresa:

El saber se sale ante todo del que ha sido su eje durante los últimos cinco siglos: el libro. Un proceso que casi no había tenido cambios desde la invención de la imprenta sufre hoy una mutación de fondo con la aparición del libro electrónico. Que no viene a reemplazar al libro sino a des-centrar la cultura occidental de su eje letrado, a relevar al libro de su centralidad ordenadora de los saberes, centralidad impuesta no solo a la escritura y a la lectura sino al modelo entero del aprendizaje por linealidad y secuencialidad implicadas en el movimiento de izquierda a derecha y de arriba abajo que aquellas estatuyen (2002, p. 178).

Teniendo en cuenta lo anterior, es interesante acotar que MartínBarbero, además de plantear el concepto de descentramiento, se refiere a la des-localización/des-temporalización de los saberes, en el sentido de que éstos escapan de los lugares y de los tiempos legitimados socialmente para la distribución y el aprendizaje, de modo tal que la escuela y la universidad ya no son los únicos ámbitos para acceder a la información y al conocimiento.

En tal sentido, vale la pena señalar que la participación en comunidades virtuales significa una apertura considerable hacia las posibilidades que plantean los hipertextos y los hipermedios como tecnologías que combinan diferentes formas de representación del objeto de conocimiento y diferentes medios interactivos, que requieren de otros procesos mentales.

En un segundo punto, dentro de la trama y las prácticas asociadas a la cultura letrada, es importante retomar el sentido del concepto de hábitus, planteado por Bourdieu (citado por Capdevielle, 2011, pp. 1-36), quien lo entiende como aquellas disposiciones durables que, integrando las experiencias pasadas, funcionan como matriz de percepciones y de acciones y posibilitan tareas infinitamente diferenciadas. En tal sentido, el hábitus de la cultura escrita, o la disposición cultural adquirida en torno al valor y al uso de los textos impresos, afecta al proceso de innovación y la apropiación de nuevos artefactos tecnológicos como los hipertextos digitales, situación que se aprecia con mayor transparencia en los sujetos adultos que han nacido y crecido bajo otras adquisiciones del conocimiento.

Para algunas personas de mayor edad los libros son objetos hegemónicos a partir de los cuales han configurado su experiencia social y, más allá esto, la subjetividad. Los hipertextos posibilitan contrastar ambos dispositivos (libro e hipertextos) y conceptualizar las singularidades que imponen al lector. Así, el libro es una tecnología invisible, con una estructura secuencial-unidireccional; la linealidad, fijación e inalterabilidad de sus palabras e imágenes marca una dirección para afrontar la experiencia social. Frente al texto impreso, fijo e inmutable, está el texto digitalizado, cuya estabilidad y fragilidad queda expuesta al sujeto:

El texto electrónico es el primer texto en que el elemento de significado, la estructura y el aspecto visual son básicamente inestables. A diferencia de la imprenta, o de los manuscritos medievales, la informática no impone que ningún aspecto de lo escrito quede determinado para toda la vida del texto. [...] Toda la información, todos los datos del mundo informático son una especie de movimiento controlado, por lo cual la predisposición natural de la escritura electrónica es hacia el cambio (Baudrillard, citado por Landow, 1995, p. 59).

Algunas respuestas dan cuenta de una resistencia a este tipo de interacciones, pero a su vez otras personas hablan de los recursos hipertextuales, apropiándose de ellos progresivamente con matices y ritmos diferentes, ya que encuentran en la red variedad de recursos didácticos (vídeos, animaciones, fotografías, sonidos y efectos especiales) que no están disponibles en los textos impresos.

\section{Saberes emergentes mediados por la colaboración y la participación}

Se hace evidente la forma en que aparecen nuevos saberes que, dados los rasgos distintivos del formato digital, se agencian 
atravesados por la colaboración y la participación en diferentes medios y contextos. De esta manera, mediante la práctica de los sujetos, dichos saberes se convierten en capitales culturales, caracterizados por la hipermedialidad, la interactividad y la intertextualidad. Se resalta, entonces, un enfoque colaborativo y, como ya se mencionó, participativo.

Así, los jóvenes convierten las interacciones en saberes culturales que, por medio de una comunidad específica, se hacen propios. La interacción es vista, entonces, desde el mismo lenguaje (chat, la navegación diaria, hablar con diferentes compañeros, etc.), posibilitando la construcción de comunidad en el intercambio de ideas, el incremento de los aprendizajes y el uso de la tecnología como medio de aprendizaje:

El discurso es un fenómeno práctico, social y cultural, y se conforma en actos sociales que generan interacción social. El discurso como secuencia se pone en funcionamiento para hacer algo, es decir, las personas utilizan el lenguaje para comunicar ideas o creencias (o para expresar emociones) y lo hacen como parte de sucesos sociales más complejos, por ejemplo, en situaciones tan específicas como un encuentro con amigos, una llamada telefónica, una lección en el aula, una entrevista de trabajo, una consulta con el médico. También cuando leen o escriben una noticia periodística (Van Dijk, 2000, p. 26).

Los jóvenes, desde su uso del lenguaje, dicen algo sobre algo en específico, dotándolo de sentido para representar, de manera significativa, el mundo a otras personas (Hall, 1997, p. 16). Esta primera manera de dar sentido a la vida a través del lenguaje permite la consideración de un código que empieza a ser compartido y a coexistir dentro de una misma cultura. De esta manera, se reconocen creencias, opiniones e incluso la oposición, es decir, ellos "hacen algo" en el sentido de que interactúan entre sí. Esta interacción que lleva a producir discursos en situaciones sociales específicas, construye y exhibe activamente diversos roles, de manera que se realizan actos como: cuestionar, oponerse, aseverar, acusar, responder o defenderse, etc. En consecuencia, los actos emergentes y comunicativos descubren los roles de los participantes:

Existe fundamentalmente para facilitar un compromiso constructivo con el mundo social y parte del supuesto de que las circunstancias existentes -incluyendo las identidades y diferencias actualmente afirmadas- no agotan el espacio de posibilidades [...] al tomarse en serio la cuestión de lo que significaría transcender la actualidad, se abre un espacio nuevo para considerar la posibilidad de que el mundo sea diferente de como es, más allá de cualquier simple afirmación de las diferencias existentes o de la tesis de que la postmodernidad es solo cuestión de perspectiva (Calhoun, 1995, p. 290).
Estas comunidades virtuales son constructoras de contenidos, productoras de sentido y manipuladoras de significados. Los usuarios no son el público-objetivo de los productos populares, sino agentes activos en la construcción y distribución de significados culturales, surgen:

A medida que nuestros vínculos con formas previas de comunidad social se van rompiendo, nuestro arraigo en la geografía física disminuye, nuestros lazos con la familia extensa e incluso nuclear se desintegran y nuestras lealtades a los Estados-nación se redefinen (Jenkins, 2008, p. 37).

Los usuarios se convierten en gestores participativos, activos en la producción compartida de significados y, en este caso, la participación se evidencia en diversos grados, desde unos niveles que podrían ser considerados elementales, hasta unos supuestamente superiores, más sofisticados (Ferrés, citado por Aparici, 2010, p. 251). Se suele asociar los primeros con procesos clásicos de recepción en los denominados medios de masas tradicionales; los últimos parecen restringidos a los nuevos entornos comunicativos. Así:

Los usuarios son interlocutores con la capacidad, no solo de consumir, sino de producir, en este caso, discursos, representaciones sociales y visiones de manera colectiva en una interacción constante y enriquecedora (Ferrés, citado por Aparici, 2010, p. 251).

La cultura participativa permite la integración de conocimiento, una construcción que se forma de manera colectiva. Los receptores se leen y apoyan y así conforman una misma visión sobre la noticia que, para ellos, carece de veracidad. Esta integración de saberes individuales lleva a crear un conocimiento compartido y colectivo mediante el intercambio de opiniones y reacciones; dichas comunidades de conocimiento: "representan una nueva forma de poder, una nueva alternativa de poder que opera junto al de los Estados-Nación, el capitalismo mercantil y el de las migraciones nómadas" (Ferrés, 2010, p. 251).

Al hablar de participación, el concepto de transformación de la sociedad se hace relevante en el sentido de que los usuarios toman conciencia y toman como compromiso, no solo individual, sino colectivo, la idea de que la realidad social tome un rumbo diferente al actual, para lograr este objetivo: "basta que la posibilidad de crear comunidades virtuales y de potenciar el trabajo en equipo se pongan al servicio de una causa potente de orden social, político o cultural" (Ferrés, 2010, p. 251). 


\section{De los deseos y placeres}

Otra de las expresiones de la subjetividad, en los jóvenes, es la capacidad de hallar en los medios digitales "deseos que se expanden $\mathrm{y}$ placeres que pueden ser vividos mediante acceso a contenidos sin filtros ni censuras" (Amador, 20014, p. 88). En medio de esta apertura de contenidos, se tiene la posibilidad de acceder libremente y sin censura a casi cualquier tipo de información o de aplicaciones que den rienda suelta a los sentimientos, deseos y pasiones.

De la misma manera se da la forma en que los participantes se encuentran, desde la singularidad y la multiplicidad de saberes, con creencias, deseos, voluntades e inteligencias colectivas (música, documentales, videos, redes, etc.). Por lo general, y como afirma Amador, estos aprendizajes se dan y se construyen desde la noción de aprendizajes invisibles, se producen y están mediados por sistemas divergentes de necesidades e intereses, que no siempre coinciden con los intereses institucionales del mundo escolar (2014, p. 115).

Así, las búsquedas de los participantes en la web están ligadas a acontecimientos de la vida, deseos y emociones que, en ciertos casos, y por algunos medios, buscan visibilizar el yo, socializar, compartir intereses, posicionar puntos de vista y utilizar contenidos para compartir, producir y reflexionar colectivamente, etc. Estos aprendizajes invisibles, contrarios a las bases de la escuela moderna, exponen prácticas no agenciadas desde la racionalidad, la reflexión y la actividad intelectual, sino desde las emociones y los deseos, desde una esfera de lo privado. Los sujetos aprenden para la vida cuando incorporan emociones y deseos; hoy día está latente, en este punto, la multiplicidad de deseos y placeres que se despliega en la red.

Desde diferentes medios se busca expresar y manifestar emociones y deseos. Se pretende encontrar posibilidades de acercamiento a otros sujetos con estas mismas prácticas. Por ello, ahora no es lejana la idea de aprendizajes solidarios, en los cuales sean las emociones las que tramiten la expresión y los saberes culturales:

Lo maquínico en términos de Deleuze y Guattari es una expresión en la que los deseos propios de las pulsiones de vida y muerte no se quedan en la individualidad, como lo planteó el psicoanálisis, sino que se incardinan en el aparato social y en las estructuras colectivas, a través de las máquinas deseantes (sujetos), las máquinas de regulación social (Estado e instituciones) y las máquinas semióticas (dispositivos que disponen la realidad de otro modo). Las máquinas deseantes, por tanto, se convertirán en el receptáculo de la actividad social y semiótica, en el que creencias y deseos podrán ser modulados y organizados alrededor de intereses subrepticios e implícitos (Amador, 2014, p. 82) ${ }^{2}$.

Para complementar, se recomienda revisar Guattari y Rolnik (2006), p. 281.

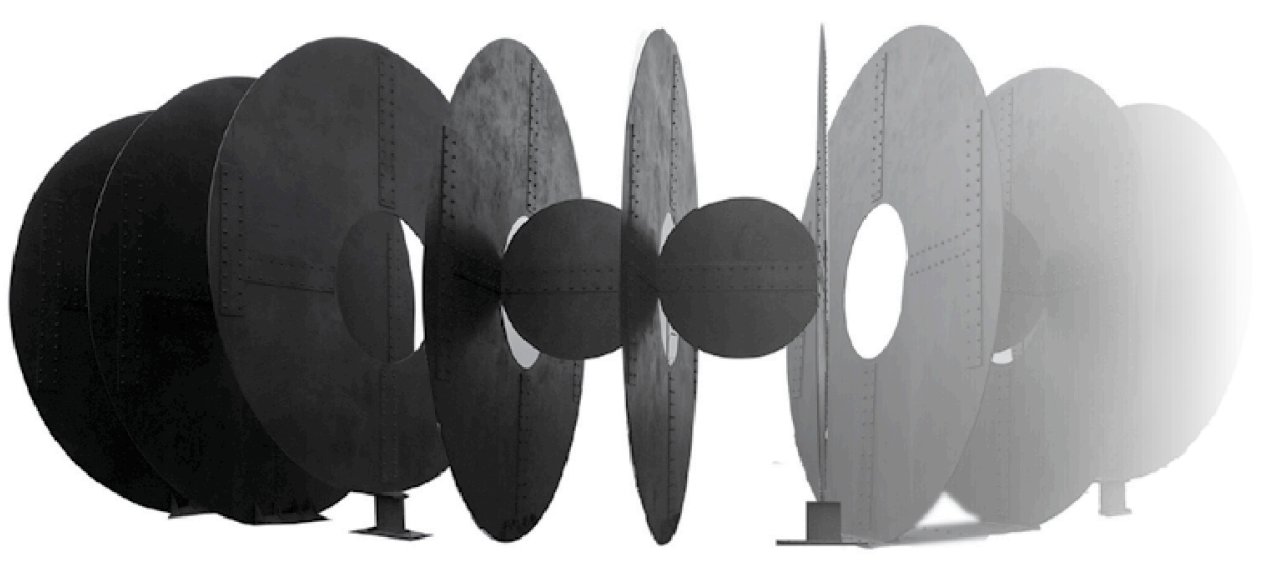




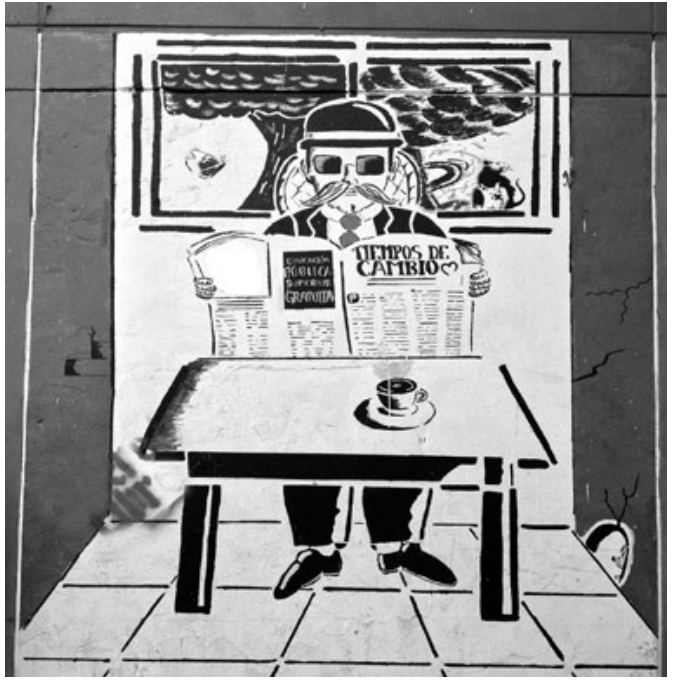

\section{Conclusiones}

Los jóvenes convierten los saberes y aprendizajes en saberes culturales que, por medio de la interacción con una comunidad específica, se hacen propios de los sujetos. La interacción es vista, entonces, desde el mismo lenguaje. Se reconoce que el chat, la navegación diaria, el hablar con diferentes compañeros, entre otros, posibilitan la construcción de una comunidad que permite el intercambio de ideas, el incremento de los aprendizajes y el uso de la tecnología como medio de aprendizaje.

De igual manera, la juventud busca expresar y manifestar emociones, pasiones y deseos mientras, al tiempo, pretende encontrar posibilidades de acercamiento a otros sujetos con estas mismas prácticas. Por ello, ahora no es lejana la idea de unos aprendizajes solidarios, en los que sean las emociones las que tramitan la expresión y los saberes culturales. En estos distintos escenarios, tan heterogéneos de subjetividades y de prácticas, se observan diferentes grados de participación e implicación, evidencia de que la apropiación de la tecnología digital excede el mero uso de herramientas y supone todo un proceso de construcción y de interpretación cultural y social, que se teje de acuerdo con el repertorio de valores y normas de cada sujeto.

Así, cada persona va configurando sus propias representaciones sobre la utilidad, la eficacia y la versatilidad de las herramientas para su práctica profesional y su formación personal, dando cuenta de una trama tan diversa como inestable, donde se confunden y se entrelazan situaciones de resistencia, indiferencia, entusiasmo y aceptación de las tecnologías, que van más allá de las condiciones del contexto social, de la cultura institucional o de los beneficios y potencial que brindan.

La representación de la subjetividad es posible a través de la interacción con los otros miembros de la comunidad. Para que sea significativa, cada uno de los participantes necesita crear su presencia virtual, en la que se evidencia el "yo" de una persona, con lo que se identifica, para después ser juzgada y/o aceptada por otros participantes del grupo. 


\section{Referencias}

Amador, J. (2010). Mutaciones de la subjetividad en la comunicación digital interactiva. Consideraciones en torno al acontecimiento en los nativos digitales. Bogotá: Signo y Pensamiento.

Amador, J. (2014). Infancias, comunicación y educación: Análisis de sus mutaciones. Bogotá: DIE.

Aparici, R. (2010). La construcción de la realidad en los medios de comunicación. Madrid: UNED.

Bourdieu, P. (1985). The social space and the genesis of groups. Theory and Society, 14 (6), pp. 723-744.

Bourdieu, P. (1991). El Sentido Práctico. Madrid: Taurus.

Bourdieu, P. (1997). Capital cultural, espacio social y escuela. Bogotá: Siglo XXI.

Calhoun, C. (1995). Critical social theory. Malden, MA: Blackwell.

Canclini, Cruces y Urteaga. (2012). Jóvenes, culturas urbanas y redes digitales. Barcelona: Ariel.

Capdevielle, J. (2011). El concepto de habitus: "con Bourdieu y contra Bourdieu”. Anduli Revista Andaluza de Ciencias Sociales, No. 10, pp. 31-35.

Csordas, Thomas. (1999). Embodiment and Cultural Phenomenology. En Gail, W., y Honi, H. (Eds.), Perspectives on Embodiment. New York: Routledge.

D’Angelo, O. (1996). Participación y construcción de la subjetividad social para una proyección emancipatoria. La Habana: Prycea.

Ferres I Prats, J. (2010). Educomunicación y cultura participativa. Educomunicación: más allá del 2.0. Madrid: Gedisa.

Ferrer, U. (2002). Opinión pública y sociedad civil en Habermas. Navarra: Servicio de Publicaciones de la Universidad de Navarra.

Foucault, M. (1982). The subject and the power. Afterword. Beyond Structuralism and Hermeneutics. Chicago: University of Chicago Press.

Guattari, F., y Rolnik, S. (2006). Micropolíticas. Cartografías del deseo. Madrid: Vozes.

Gumbrecht, H. (2005). La producción de presencia y las humanidades. Bogotá: Nómadas.

Hall, S. (1997). Representation. Cultural Representations and Signifying Practices. Londres: Sage.

Hall, S. (2004). Codificación y descodificación en el discurso televisivo. Londres: CIC.

Heeter, C. (1992). BattleTech masters: Emergence of the first U.S. virtual reality subculture. Multimedia Review, 3(4), pp. 65-70.

Jenkins, H. (2008). Convergence culture. La cultura de la convergencia de los medios de comunicación. Barcelona: Paidós.

Landow, G. (1995). Hipertexto. La convergencia de la teoría crítica contemporánea y la tecnología. Buenos Aires: Paidós.

Laurel, B. (1991). Computers as theater. Reading, MA: Addison Wesley.

Machado, G., Gómez, L., y Espina, R. (2008). La juventud y los retos de la actualidad en Cuba, siglo XXI. IV Conferencia Internacional "La obra de Carlos Marx y los desafíos del siglo XXI. Obtenido desde http://www.nodo50.org/cubasigloXXI/ congreso08/conf4_machadogr.pdf

Martin-Barbero, J. (1991). De los medios a las mediaciones. Comunicación, cultura y hegemonía. Barcelona: Gustavo Gili.

Martín-Barbero, J. (2002). La crisis de las profesiones en la "sociedad del conocimiento". Bogotá: Nómadas.

Organisation for Economic Cooperation and Development. (OCDE). (2004). Regulatory reform as a tool for bridging the digital divide. OECD Digital Economy Papers, No. 90. Obtenido desde http://www.oecd.org/dataoecd/40/11/34487084.pdf

Pérez, J. (2002). Políticas de juventud del nuevo siglo: para mirar lo que vemos. Actores estratégicos para el desarrollo. Políticas de Juventud para el siglo XXI. México: Centro de Investigación y Estudios sobre Juventud. Obtenido desde http://cendoc. imjuventud.gob.mx/clr/libros/libros.php?libro=011

Rueda, R. (2012). Subjetividades, ciudadanías y tecnologías digitales. Bogotá: Diálogos de la comunicación.

Van Dijk, T. (2000). El discurso como estructura y proceso. Madrid: Gedisa.

Weiss, G., y Haber, H. (1999). Perspectives on Embodiment: The Intersections of Nature and Culture. Routledge, pp. 143-62. 